\title{
O Xamanismo Indígena Guarani como Expressão Demônica da Cultura
}

\author{
Gustavo Soldati Reis*
}

\begin{abstract}
RESUMO
Esse texto analisa algumas possibilidades de diálogo hermenêutico entre a Teologia da Cultura de Paul Tillich, especificamente em relação a seu conceito de demônico, com a antropologia da religião indígena, especificamente em relação à dimensão ambígua do xamanismo Guarani. Nesse sentido, a partir de uma breve introdução, o texto conta com uma caracterização geral do demônico e uma definição mais formal do xamanismo. Por fim, a percepção de algumas implicações, em torno da hipótese da figura do xamã/rezador (enquanto mediador simbólico em contextos de profundos processos de desterritorialização e intenso pluralismo religioso), como agente social da experiência sagrada de criação e distorção de sentidos da vida, síntese dialética entre religião e cultura que perfaz a noção tillichiana do demônico.

Palavras-chave: xamanismo; guarani; demônico; Paul Tillich; religião e cultura; hermenêutica.
\end{abstract}

THE GUARANI INDIGENOUS SHAMANISM AS A DEMONIC EXPRESSION OF CULTURE

\begin{abstract}
This text analyses some possibilities of hermeneutical dialogue between Paul Tillich's theology of culture, regarding his concept of demonic with the anthropology of indigenous religion and the ambiguous dimension of
\end{abstract}

* Graduado em Teologia. Doutor em Ciências da Religião pela Universidade Metodista de São Paulo - UMESP. Professor Adjunto I do Departamento de Filosofia e Ciências Sociais e do Programa de Pós-Graduação (Mestrado) em Ciências da Religião da Universidade do Estado do Pará - UEPA, em Belém. E-mail de contato: gsoldatir@gmail.com. Lattes: http://lattes.cnpq.br/9780821625087052. Esse texto teve como motivação, originalmente, uma comunicação apresentada no Terceiro Congresso da Associação Nacional de PósGraduação e Pesquisa em Teologia e Ciências da Religião - ANPTECRE, realizado em São Paulo em maio de 2011. Aqui o texto aparece corrigido e ampliado. 
the Guarani shamanism. The paper offers a general characterization of demonic as well as a formal definition of shamanism. The perception of some implications around the hypothesis of the shaman/prayer (the symbolic mediator in contexts of deep processes of no-territorialism and intense religious pluralism), as a social agent of the sacred creation experience and distortion of the sense of life, relies on a dialectical synthesis between religion and culture that characterizes Tillich's thought about the demonic. Keywords: shamanism; guarani; demonic; Paul Tillich; religion and culture; hermeneutics.

\section{Introdução}

Começo esse artigo com uma frase do poeta Ricardo Reis, heterônimo de Fernando Pessoa: "Vivem em nós inúmeros: [...] Tenho mais almas que uma. Há mais eus do que eu mesmo"1. Essa frase sugere uma boa metáfora para a prática do xamanismo indígena, em particular o xamanismo Guarani. O xamã é um transeunte constante: sua alma/ pessoa pulsa na pluralidade, pois ele caminha por inúmeros mundos de sentido construídos por múltiplos atores sociais. No xamã habitaria, como diz o poeta, "mais eus" do que ele mesmo, na busca por traduzir os horizontes de sentido que configuram os espaços sociais indígenas em meio a muitos processos de fragmentação e tensão vividos por esses mesmos espaços sociais. Existem estudos de referência na etnologia brasileira sobre o protagonismo xamânico em relação a diversos grupos étnicos indígenas, tanto nas terras baixas amazônidas (caso dos estudos dos antropólogos Eduardo Viveiros de Castro e Carlos Fausto, respectivamente sobre os Araweté e os Parakanãs) como fora delas (no Mato Grosso do Sul, por exemplo, em relação aos grupos étnicos Ñandeva e Kaiowá referentes aos estudos de Fábio Mura e Levi Pereira) ${ }^{2}$. Viveiros de Castro (2015, p. 172-3), por exemplo, afirma que, na constituição social dos mundos naturais que os indígenas habitam, a atividade xamânica “(...) consiste no estabelecimento de correlações e traduções entre os mundos respectivos de cada espécie natural" onde o xamã é o agente que, continuamente, se coloca em diferentes pontos de vista formulados

PESSOA, Fernando. Poesias, p. 116.

2 Todas essas quatro etnias que habitam, atualmente, diferentes regiões do Brasil pertencem ao tronco linguístico Tupi-Guarani. Sobre os textos dos quatro antropólogos mencionados, encontram-se alguns nas referências bibliográficas ao final do artigo. 
e, não raro, em conflitos. Colocar-se "em diferentes pontos de vista" é, em certa medida, constituir-se enquanto um mediador de interpretações e de sentidos para os grupos étnicos a qual fazem parte. Isso significa, principalmente no Brasil atual, que o xamã assume processos de gestão simbólica representativa de muitos "eus" (humanos e "não-humanos") em situações cheias de contradições, não raro violentas, pois operam em contextos de desterritorializações de suas terras tradicionais. Por hipótese, eles fazem a gestão de experiências religiosas, o que rebate nas dimensões culturais e políticas, de processos criativos e distorcidos, ou seja, das ambiguidades da vida, ambiguidade essa como categoria compreensiva e não meramente uma adjetivação da realidade.

Essas perspectivas nos remetem ao teólogo e filósofo Paul Tillich (1886-1965) que, por sua vez, não fez específicas correlações entre seu pensamento filosófico e teológico com as ciências etnográficas, muito embora tenha situado essas no horizonte dos saberes que tem por objeto as formas culturais. Todavia, Tillich exercitou o pensamento de fronteira, ou seja, tornou-se um caminhante existencial e intelectual no limite de diversos saberes e experiências, entre os quais as fronteiras entre religião e cultura, como ele próprio enfatiza, por exemplo, em seu "esboço autobiográfico" intitulado On the Boundary ${ }^{3}$. Parece que no pensador germano-americano habitava, a modo do poeta citado no início do texto, mais eus do que ele mesmo. Nessa relação fronteiriça entre religião e cultura surge, em particular, a noção de demônico. Essa noção é um bom lugar hermenêutico para se repensar essa fronteira, principalmente quando essa fronteira é expressa pela experiência religiosa e cultural xamânica presente em várias sociedades indígenas Guarani no Brasil. Esse conceito radicaliza a profundidade tensiva que caracteriza as formas culturais, uma vez que a substância religiosa que as fundamenta também não prescinde dessa tensividade. O próprio Tillich afirma, ainda em sua fase de produção alemã: "O demônico está fundamentado sobre uma tensão entre a criação e a destruição das formas" (TILLICH, 1990, p. $127)^{4}$. Como ele afirmava claramente, não confundir com demoníaco ou

\footnotetext{
3 Em uma tradução livre seria Na Fronteira. Sobre as relações entre religião e cultura, nesse texto, página 68ss. Texto original de 1966.

4 Tradução de: "Le démonique est fondé sur une tension entre la création et la destruction des formes (...)“. Trata-se do projeto de tradução das Gesammelte Werke de Tillich para o francês. Aqui a citação faz parte do texto de Tillich intitulado O Demônico, publicado em 1926.
} 
satânico. Ao contrário, mais do que uma força de destruição, o demônico comporta uma criação distorcida, ambígua.

Assim, uma das marcas características da noção de demônico, no que diz respeito à experiência religiosa é, justamente, a ambiguidade. Essa noção pode ser útil para se repensar os dilemas que as práticas xamânicas Guarani tradicionais enfrentam hoje. Esses enfrentamentos ocorrem, conforme afirmei, nas fronteiras de tensão de suas tradições de conhecimento com os profundos processos de desterritorialização e confinamentos sociais e culturais vividos no âmbito das reservas (BRAND, 1997). Além disso, a própria noção e papel social dos rezadores/xamãs hoje, vive as tensões das múltiplas fronteiras interculturais com várias faces do missionamento cristão, operando uma tradução da tradição de conhecimento nativa ao ressignificar as práticas xamânicas ditas tradicionais. Portanto, um contexto de radical ambiguidade. Assim, algumas questões que esse artigo coloca para as reflexões são: em que perspectivas o xamanismo pode ser considerado à luz do conceito de demônico em Tillich e, por outro lado, que possíveis implicações para o diálogo entre religião e cultura, no âmbito da fronteira entre antropologia e teologia, pode ser percebido nesse possível diálogo? São questões provocadas nesse texto que tem por objetivo semear apenas algumas hipóteses em reflexões ainda preliminares. Sigamos, pois, em frente.

\section{A invenção do xamanismo e do demônico. Percursos e percalços}

\subsection{Perspectivas sobre o Demônico 5}

Por mais que a noção de demônico perpasse toda a Teologia Sistemática de Tillich ${ }^{6}$ (em que pese os problemas de tradução do termo), nos mais de 10 anos em que os três volumes originais levaram para ser publicados, a construção desse conceito é bem anterior, remontando sua

\footnotetext{
Esse subitem é um breve trecho que, originalmente, faz parte do segundo capítulo de minha tese de doutorado intitulada Ambiguidade como inventividade: um estudo sobre o sincretismo religioso na fronteira entre Antropologia e Teologia, defendida em 2010. Encontra-se em um subitem do referido capítulo intitulado Religião como criação "demônica". Um bom texto acerca da noção de demônico em Tillich é o do cientista da religião Eduardo Rodrigues da Cruz intitulado A Dupla Face: Paul Tillich e a Ciência Moderna, em especial o item Ambivalencia (Ambiguidade) no pensamento de Paul Tillich, p. 105-43.

6 Principalmente na parte 4 A Vida e o Espírito, item I intitulado $A$ Vida, suas ambiguidades e a busca da vida sem ambiguidade, p. 475-566.
} 
fase alemã. De acordo com Carlos Calvani, a primeira menção do demônico em Tillich ocorre em um artigo de 1923 intitulado Os princípios fundamentais do Socialismo Religioso (Grundlinien des religiösen Sozialismus). Mas vai ser somente em 1925, na obra Filosofia da Religião, que a noção começa a se impor na sua relevância hermenêutica para a análise das relações entre religião e cultura ${ }^{7}$. Jean Richard também afirma a importância do demônico em diversos escritos de Tillich na fase de produção de seu programa de filosofia e teologia da cultura, nos anos de 1919 a 1926, onde Tillich procurou pensar exaustivamente a mediação compreensiva entre o absoluto da religião e a autonomia das formas culturais: "Tillich oferece aqui sua nova concepção da religião como conteúdo e substância de toda forma cultural, como fundamento do sentido e profundidade inspiradora de toda criação cultural" (RICHARD, 1990, p. 10) ${ }^{8}$.

A partir de uma leitura fenomenológica e filosófica, Tillich passa a conceber o demônico como o símbolo radical para a essência ambígua do sagrado, cunhando os pólos sagrado-divino e sagrado-demônico. Assim, tanto as formulações míticas das religiões quanto a estrutura psíquica e social dos seres humanos, em seu nível mais íntimo, evocam a profundidade demônica, ou seja, abissal, obscura, ambígua, na busca pelo sentido da existência (RICHARD, 1990, p. 15). O próprio Tillich afirma que o demônico se realiza no espírito, na personalidade e nos domínios sociais e culturais, ou seja, esses são os lugares do demônico (TILLICH, 1990, p. 130). Importante frisar: não é uma dimensão puramente positiva ou negativa, mas ambígua, da mediação. Com isso Tillich procura mostrar como essa ambiguidade se desenvolve na história das religiões, pontuando as projeções mais existenciais sobre as forças demônicas do presente (no caso, o período entre guerras da primeira metade do século XX)9 . Para Rodrigues da Cruz o demônico é o equivalente religioso da ambiguidade, uma vez que parte da própria noção ambígua

CALVANI, Carlos E. B. Imagens do Diabo na MPB. In: HIGUET, Etienne A. e MARASCHIN, Jaci C. (eds.). A Forma da Religião. Leituras de Paul Tillich no Brasil, p. 166.

8 No original: "Tillich propose ici sa nouvelle conception de la religion comme contenu et substance de toute forme culturelle, comme fondement du sens et profondeur inspiratrice de toute création culturelle".

9 Para maiores matizações sobre a noção de Demônico na fase alemã de Tillich, ver o texto Filosofía de la Religión, em especial o item Los elementos esenciales de la religión y sus relaciones, p. 61-76. 
de sagrado assumida pelo teólogo alemão e afirmada no início desse parágrafo. Nos processos de criação da vida, dirá Tillich no próprio ensaio intitulado O Demônico, de 1926, há uma total impossibilidade de ocorrer criações totalmente controladas e racionais: na dinâmica da vida cultural, por conta de sua substancialidade religiosa, o divino não deve prescindir de seu abismo e profundidade demônica, assim como o demônico não pode deixar de ser visto, ainda que de forma tensa, com a clareza do divino (RODRIGUES DA CRUZ, 2008. p. 136).

Tillich afirma que o lugar do demônico é, essencialmente, a experiência espiritual dos seres humanos. Mas é bom não esquecer que com espiritual aqui evoca-se a experiência de sentido e não a relação com seres espirituais chamados de demônios. Como é marcada por preocupações/sentidos incondicionais, a essência do demônico é religiosa. Isso significa também que a percepção do demônico passa pelas formas culturais mas não se esgota nelas. Ao expressar-se nas mediações culturais, o demônico ganha dimensões sociais e antropológicas, além de expressar-se nas estruturas individuais do ser humano. Mas seu fundamento é a experiência do sentido (TILLICH, 1990, p. 1304). Essas dimensões de compreensão do demônico são retomadas nas possíveis relações desse conceito com a teologia sistemática. Por se tratar da relação com o pensamento teológico, Tillich procura deixar claro que a concepção do demônico não pode ser confundida com um mero apêndice às elaborações sobre o pecado, a modo das dogmáticas tradicionais. Procura, assim, perceber as implicações éticas e sociais da noção ambígua de demônico para todos os campos da Teologia, em particular a cristologia e a eclesiologia (RICHARD, 1990, p. 16).

Mais uma vez Jean Richard (1990, p. 20) sintetiza a compreensão desse conceito ao afirmar: "O Dämonisch [Demônico] significa, por outro lado, um princípio ambíguo, que comporta um elemento criador e um elemento destruidor. Isto é, a face obscura do fundamento abissal [...] Poderíamos até dizer que é a perversão do sagrado, o sagrado com

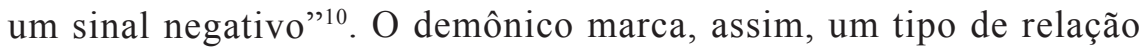
essencial, um princípio que se estabelece entre a substância religiosa

10 No original: "Le "Dämonisch" signifie en revanche un principe ambigu, qui comporte un élément créateur et un élément destructeur. C'est la face obscure du fondement abyssal (...) On pourrait dire encore que c'est la perversion du sacré, le sacré avec un signe négatif". 
e as formas culturais nas quais se expressa. E que tipo de princípio, mais especificamente, seria? Um princípio inventivo, tanto na essência do sagrado e de sua expressão religiosa, quanto na mediação com as formas culturais, ou seja, na busca e compreensão da unidade de sentido e significação última da existência a condição humana inventa espaços de sentido criativos ou espaços distorcidos, até mesmo destrutivos. Eis os paradoxos, em perspectiva dialética. Em outro texto de 1926 intitulado $O$ conceito do Demônico e sua significação para a Teologia Sistemática, Paul Tillich afirma:

A possibilidade do demônico repousa sobre o fato de que o sagrado é sempre ao mesmo tempo esse que porta e que reivindica incondicionalmente; que é ao mesmo tempo profundidade e forma, abismo e fundamento, e que na criatura os dois podem se separar ${ }^{11}$

$\mathrm{Na}$ citação, em acento fenomenológico, a expressão do sagrado se manifesta à consciência da criatura como uma profunda ambiguidade: assim, a religião dá suporte enquanto sentido, fundamento, mas vai além, se "perde", é abismo. Com isso, a questão problematizada por Tillich é: se as formas culturais deixam transparecer criativamente o fundamento religioso ou se distorcem e resistem à percepção desse fundamento. Nessa fratura, nessa ruptura, instaura-se o demônico, pois provém da própria ambiguidade do sagrado, divino e demônico ao mesmo tempo, conforme afirmado. Em síntese:

[...] é razoável argumentar que Tillich, pelo menos durante o período germânico, caracteriza o demônico como ambíguo, e os demonismos do presente alternadamente como demônicos e ambíguos. O demônico deve ser, então, a dinâmica subjacente, criativa e destrutiva, implicada nas ambigüidades da vida. É a "profundeza" da ambigüidade, por assim dizer. Por isso, os demonismos podem ser vistos como as realidades históricas ambíguas, consideradas sob o seu aspecto transcendente, isto é, sob sua possibilidade de auto-elevação (RODRIGUES DA CRUZ, 2008, p. 137)

11 No original: "La possibilite du démonique repose sur le fait que le sacré est toujours en même temps ce qui porte inconditionnellement et ce qui revendique inconditionnellement; qu'il est en même temps profondeur et forme, abîme et fondement, et que dans la créature les deux peuvent se séparer». In : RICHARD, 1990, p. 156. 
É importante, por hipótese aqui, antecipando aspectos do próximo item, pensar o xamanismo dentro da experiência do demônico como arrojar-se, do lançar-se, de colocar-se nessa ruptura, maneira de renomear os caminhos e travessias xamânicas. Nesse sentido, demônicas. O universo xamanístico pode ser lido a partir da metáfora do abismo, tão cara a Tillich. O xamanismo constitui-se em um movimento de lançar-se no abismo das relações de sentido cósmicas, que nunca pode ser conclusivo, sempre protelado, pois a experiência do sagrado sempre coloca a possibilidade de contato com outras alteridades, retomando o movimento de criação e desagregação, de aproximações e afastamentos, de encontros e desencontros. $\mathrm{O}$ foco não se encontra em nenhum dos pólos, embora não possa prescindir dos mesmos. O foco encontra-se no processo de mediação. Quanto mais o gradiente de sentido consegue se manter no meio, mais sentido se produz a partir das experiências compreensivas. Quanto mais o gradiente se desloca para um dos pólos, mais se distorce e se produz os sem-sentidos a partir das experiências religiosas vividas. Quando os xamãs $\backslash$ rezadores indígenas fazem seus movimentos de irem e retornarem, em seus transes e êxtases religiosos, aos mundos representativos de suas cosmologias o fazem nessa perspectiva desse processo de mediação descrito. Falaremos mais sobre esses processos no próximo item.

\subsection{Perspectivas sobre o xamanismo}

A literatura especializada sobre as tradições xamânicas de grupos étnicos Guarani no Brasil é amplamente conhecida, contando com etnografias clássicas, desde Curt Nimuendajú e Egon Schaden até Bartomeu Meliá e o casal Grünberg ${ }^{12}$. Conta, também, com importantes análises de cunho mais formal, amparados em uma ousada antropologia política e filosófica sobre esses grupos, tais como os importantes estudos de Pierre Clastres e Eduardo Viveiros de Castro $^{13}$, só para ficar nesses exemplos.

12 O texto de Nimuendajú chama-se As Lendas da Destruição e Criação do Mundo como fundamentos da Religião dos Apapocúva-Guarani, publicado, originalmente, em 1914. De Schaden o texto é Aspectos Fundamentais da Cultura Guarani, cuja primeira edição foi em 1954. De Meliá e de Georg e Friedl Grünberg o texto é Etnografia Guarani del Paraguay contemporâneo, primeira edição de 1976. Diferentemente dos anteriores, esses últimos pesquisaram os Pai Tavyterã do Paraguai.

13 De Viveiros de Castro o texto A Inconstância da Alma Selvagem. Trata-se de uma coletânea de textos publicada em 2001. De Clastres o texto A Sociedade contra o Estado publicado, originalmente, em 1974. 
Na concepção de Viveiros de Castro, o xamanismo pode ser percebido como uma experiência de fronteira, sendo o termo fronteira tomado como expressão significativa muito importante para o pensamento de Tillich. Os múltiplos cosmos aos quais ele (o xamã/rezador) transita, apresentam diferentes perspectivas. Ele precisa negociar, constantemente, essas perspectivas que instauram regimes de poder: "[...] seu poder, e os limites de seu poder, derivam dessas diferenças" (VIVEIROS DE CASTRO, 2002, p. 469). O demônico, por sua vez, em Tillich, é um recurso teórico que medeia a relação entre religião e cultura no plano da significação, da experiência de sentido. Falar de demônico, nesse aspecto, é falar do risco que as experiências religiosas enfrentam em afirmar criativamente o sentido da experiência sem destruir (respeitando) as formas (culturais) concretas em que se manifestam. Essa polaridade entre criação e destruição é propositiva para se repensar a experiência xamânica Guarani. Assim, o xamã coloca-se na difícil tarefa de viver no limiar/fronteira de se repensar a alteridade, pois assumir uma perspectiva criativamente pode implicar na destruição e desagregação de outras perspectivas. Novamente citando Viveiros de Castro: “O xamanismo pode ser definido como a capacidade manifestada por certos humanos de cruzar as barreiras corporais e adotar a perspectiva de subjetividades não-humanas" (VIVEIROS DE CASTRO, 2002, p. 468). A realidade, para o xamanismo Guarani, não opõe natureza e cultura. Essa mesma realidade cósmica é social, onde os xamãs, em seus caminhos cósmicos a transformam em uma grande arena onde se manifestam disputas, elaboram-se estratégias, buscam-se alianças, exerce-se dominação e busca de equilíbrio, não totalmente alcançado (MURA, 2006, p. 304ss).

É muito complexo pensar o xamanismo, por exemplo, no contexto das terras indígenas Guarani no Brasil onde muitas delas, ao tornarem-se reservas $^{14}$, constituem-se em verdadeiros lugares de produção material

14 Reservas, justamente, por se tratar de processos de demarcação de terras levado a cabo pelo governo brasileiro (antigo Serviço de Proteção ao Índio - SPI, hoje FUNAI - Fundação Nacional do Índio) ao longo de décadas. Nesses processos não são raro os conflitos de interesses políticos, econômicos e antropológicos entre agências diversas, o que tornam esses processos muito complexos: da passagem das terras tradicionais para reservas que, nem sempre, respeitam as territorialidades tradicionais. Veja-se o emblemático caso da Reserva Indígena de Dourados, no Estado de Mato Grosso do Sul, nomeada "Francisco Horta Barbosa", reservada pelo Decreto 401, de 1917, com a titulação definitiva das terras, aproximadamente $3.475 \mathrm{ha}$, somente em 1965 . Essa reserva é povoada por um contingente expressivo de indígenas Guarani Kaiowá e Ñandeva que, historicamente, tiveram que habitar em lotes de terras longe de suas terras tradicionais. Cf. VV.AA. Povos Indígenas no Brasil. 2001\2005. Instituto Socioambiental, p. 783. 
e simbólicos altamente tensivos, devido aos profundos processos de criação, resistências, porém, de violentações históricas que esses povos ainda vivem nesses contextos. Em um sentido mais tillichiano diria que há uma conjunção de elementos heterônomos que pressionam as autonomias tradicionais desses povos Guarani na configuração de sua práxis social. Elementos esses que tentam eliminar as ambiguidades mas que acabam sacrificando, por isso mesmo, as muitas perspectivas que as lideranças indígenas tradicionais, entre os quais os xamãs/ rezadores, têm que lidar. A compreensão do demônico, nesse sentido, fica refém de profundas distorções absolutistas, ou seja, experiências demoníacas, pois o que o demônico, reflexivamente ensina, é a impossibilidade de se pensar a religião fora da ambiguidade. Ao efetivar suas experiências de transe religioso o xamã opera, por hipótese, um conflito de perspectivas, pois coloca à prova suas intencionalidades significativas em relação às múltiplas alteridades que representam o sagrado no plano cósmico. Se o mundo social dos indígenas é ambíguo isso é assim porque, por hipótese, o mundo das relações cósmicas (divindades e tekojaras) ${ }^{15}$ também é. Esses seres também vivem um processo de constantes ressignificações de sentido, ora estabelecendo relações positivas ora estabelecendo relações distorcidas.

É sempre bom deixar claro a centralidade do complexo xamanístico para a experiência religiosa e cultural dos Guarani, conforme aponta algumas das etnografias citadas no início desse item. Para situar esse aspecto cito, novamente, o antropólogo Fábio Mura:

[...] xamãs, únicos sujeitos que, como vimos, podem viajar por todas as dimensões e partes do Cosmo, dialogando e interagindo com os seres que as povoam. O xamã é, portanto, figura central na tradição de conhecimento indígena, sendo ele quem tem a legitimidade para avaliar moral e eticamente os saberes que circulam e estão à disposição dos índios (MURA, 2006, p. 304)

15 Expressão Guarani que pode ser traduzida por “O dono/senhor do meu jeito de ser". Cada elemento "natural" (plantas, animais, seres humanos), por serem profundamente sociais, comportando-se como humano, apresentam seus "jara" (donos). Ao xamã espera-se, no trânsito religioso entre os diversos patamares do Cosmos negociar, constantemente, com esses "jara" para a boa ordenação do mundo social dos indígenas. 
Na realidade, o que parece incomodar na noção de demônico e de sua possível implicação para a questão do xamanismo é que a experiência da distorção (e o risco da absoluta destruição do sentido) não deixa de ser, paradoxalmente, uma criação também. Excesso de subjetividade quando a ciência pede mais objetividade? Pode ser, mas como diz Viveiros de Castro, em relação à epistemologia ameríndia, principalmente em relação ao xamanismo, as intencionalidades subjetivas é que moldam o real (VIVEIROS DE CASTRO, 2002, p. 488). Assim, as avaliações morais e éticas da circulação de saberes da citação de Mura, colocam sob o xamã uma responsabilidade enorme, pois ele opera a experiência de produzir sentidos religiosos fundamentais para as suas comunidades, sabendo que a produção de sentido, se levar em conta a ambiguidade do demônico, pode evocar saberes distorcidos. O xamã vive, pois, nesse limiar da criação e destruição.

Para tanto, voltemos à compreensão da cosmologia Kaiowá, por exemplo. Não há, nessa cosmologia, um forte dualismo entre natureza e cultura ou entre estas e um mundo tido por sobrenatural. De acordo com Mura, "Todos os elementos do universo encontram-se na condição de agir ou serem agidos por outros, sendo as diferenças determinadas através de níveis de eficácia e de hierarquia relacional, e não através de dicotomias ontológicas" (2010, p. 132-33). Para chegar ao tempo presente, que muitos Kaiowá nomeiam por Áry Ypyrã (o "espaço-tempo atual"), o cosmos passou por muitas etapas e processos, com suas respectivas ambiguidades. O tempo e espaço atual é violento, iniquo, de profundas relações de poder assimétricas. Os Kaiowá, descendentes das divindades originais devem buscar, incessantemente, reproduzir o modo de vida equilibrado de tempos pretéritos, os "tempos originais", o Áry Ypy, reproduzindo o "bom jeito de ser" (o Teko Porã). Além disso, esse tempo e espaço atual são povoados pelos járy ${ }^{16}$, ou seja, o conjunto de "donos", "senhores" de todos os seres, de todos os coletivos humanos que habitam a terra e os diferentes patamares celestiais, mesmo que muitos humanos não se apresentem, aparentemente, como tais, travestidos por sua "roupagem" animal, por exemplo. Assim, os Kaiowá lutam constantemente com os males da terra atual, em intensa relação com esses seres para, simbolicamente, reatualizar a situação

16 Veja nota de rodapé anterior. 
ideal de seus ancestrais míticos. Daí reside, dentre outros aspectos, a importância dos xamãs: eles se situam em uma tradição de conhecimento dos ñengáry, ou seja, um conjunto de preces comunicadas a eles diretamente e, exclusivamente, pelas divindades, divindades essas que são, também, marcadas por profundas ambiguidades de relação. Novamente citando Mura:

Na comunicação com os Ñande Ryke'y, os xamãs (denominados ñanderu) recebem constantemente o tekorã, isto é, o modo de ser que deverá vigorar em cada contexto histórico. Assim, contribuem para a construção e a transformação constantes da moral indígena e do corpus de conhecimentos considerados importantes para o bem-estar social e familiar (MURA, 2010, p. 134) ${ }^{17}$

Ir e voltar desses mundos e dessas relações interpretativas do conhecimento das divindades e dos muitos jaras, perfaz os caminhos do xamanismo indígena. Ou seja, eles são uma espécie de agenciadores das performances demônicas dos diferentes seres e deles próprios, uma vez que têm que lidar, continuamente, com as situações limites de falas e ações que constroem e distorcem o mundo de sentido e seu rebatimento na construção social da realidade. É possível evocar aqui, também, a teoria clássica do antropólogo escocês Ioan Lewis. Para Lewis o xamanismo evoca, também, uma ambiguidade radical: não se trata somente de que os espíritos "possuem" o xamã, mas o próprio xamã "possui" o espírito:

A palavra tungue xamã (pronunciada samã entre os vizinhos manchus) significa literalmente "alguém que está excitado, comovido ou elevado" (e isto, incidentalmente, é muito semelhante às conotações de outras palavras em outras línguas, empregadas para descrever a possessão). Mais especificamente, xamã é uma pessoa de qualquer sexo que dominou os espíritos e que pode, à sua vontade, introduzi-los em seu próprio corpo. De fato, ele freqüentemente encarna esses espíritos e pode controlar suas manifestações, caindo em estados controlados de transe em circunstâncias apropriadas (LEWIS, 1977, p. 58)

17 Nesta citação o termo Nande Ryke'y pode significar “nossos irmãos mais velhos”. Por sua vez o autor grafa o termo ñanderu com a inicial minúscula para diferenciar de Ñande $\mathrm{Ru}$ (“Nosso Pai"), com inicial maiúscula. Este se refere a uma das divindades maiores do panteão mítico dos Guarani Kaiowá. Aquele a forma nativa como os Kaiowá denominam o que chamamos de xamã ou rezadores. 
$\mathrm{Na}$ realidade, é preciso entender essa relação dialética no horizonte dos paralelismos que Lewis estabelece entre xamanismo e possessão. Se os xamãs são "mestres de (e não do) espíritos", expressão que Lewis toma emprestado de outro antropólogo, o neozelandês Raymond Firth, isso não significa, no caso dos rezadores Guarani que há, necessariamente, uma incorporação de espíritos por parte desses mesmos rezadores. O êxtase religioso a que esses rezadores experimentam é a possibilidade de "possuírem" o controle das negociações dos jara. Nesse caso, é possível amparar-se em Lewis para dizer que os rezadores Guarani é que "possuem" seus jara, ou seja, em um acento mais perspectivista, assumem a situação/ponto de vista desses mesmos jara. Basicamente é como se o xamã, em sua experiência religiosa, fosse uma caixa de ressonância, interpretando e reverberando, para seu grupo social, as múltiplas vozes, sons, mensagens, produções de sentido e seus conflitos interpretativos que cada ser, na cosmologia Guarani, também executa. Pode ser um exemplo de experiência cultural, a partir de sua fundura religiosa, da dinâmica subjacente das criações e distorções das ambiguidades da vida característica do demônico.

\section{Implicações para o diálogo}

É possível, para caminharmos dentro dessa parte final do texto, semear algumas hipóteses a mais em resposta à questão central: em quais sentidos, baseado nas discussões anteriores, o xamanismo pode ser traduzido por uma perspectiva demônica?

1. Primeiramente, no poder de reinvenção dos percursos de sentido em torno da experiência religiosa. Se, para Viveiros de Castro, o complexo xamânico é bem descrito a partir de seu conceito de perspectivismo ameríndio, o que significa "[...] a concepção indígena segundo a qual o mundo é povoado de outros sujeitos ou pessoas, além dos seres humanos, e que vêem a realidade diferentemente dos seres humanos", ou seja, "um processo de por-se no lugar do outro" (VIVEIROS DE CASTRO, 2002, p. 480), isso faz do xamanismo uma experiência da radical ambiguidade, posto que do xamã espera-se a capacidade de interpretar as intencionalidades dos vários atores sociais que habitam seu universo de sentido, além de suas próprias intencionalidades. 
A perspectiva tillichiana do demônico de que a experiência religiosa, sob as condições da existência (formas culturais), acontece na tensão de exprimir sentidos preliminares e, mais importante, incondicionais, ao mesmo tempo do risco da crise e da perda do sentido, demanda do sujeito religioso a capacidade de reinvenção de suas perspectivas e práticas. Isso é particularmente importante no caso do xamanismo Guarani, dentro das experiências de êxtase religioso, por exemplo. As danças e rezas (nomeadas em guarani por porahêi) são momentos culturais privilegiados onde se percebe uma substancialidade religiosa demônica: cada dança e fala ritual é a construção de caminhos e a possibilidade de descaminhos de sentido nas relações sociais, por exemplo, com os tekojara, ou seja, os donos do modo de ser de cada um (conforme dito, humanos e animais. Nesse sentido, os animais possuem seus xamãs também...). É preciso um incrível poder de negociação de interesses e perspectivas para que as demandas sociais dos grupos Guarani sejam satisfeitas. Por isso, a dificuldade e resistência de encontrar xamãs que partilhem, a fundo, suas palavras-reza àqueles que, segundo suas perspectivas, podem destruir mais do que construir caminhos de diálogo: nesse sentido, a polaridade criação e destruição pode ser um ponto importante de aproximação entre as práticas xamânicas e a categoria hermenêutica do demônico, uma vez que a experiência religiosa xamânica Guarani, na feliz expressão de Pierre Clastres, é um constante agenciamento entre a vida e a morte, o sentido e o sem-sentido, tanto no plano social quanto individual, algo que não estaria tão distante assim das perspectivas do demônico ${ }^{18}$.

2. Por mais que a noção de demônico em Tillich inscreva-se na perspectiva de uma filosofia do sentido, não é possível desvinculá-la dos espaços de relações sociais concretas, pois a perspectiva do sentido ou do sem sentido depende das relações que a substância religiosa estabelece com as formas culturais, se assim podemos nos exprimir. De fato, Tillich sempre procurou fazer análises de situações culturais pontuando o risco dessas formas culturais não transparecerem a substância de sentido incondicional, ou seja, o risco da participação distorcida nessa substância religiosa, o demônico, criar o efeito deletério e idolátrico do demoníaco. Esse tema das relações de poder estabelecidas entre

18 Cf. CLASTRES, Pierre. A Sociedade contra o Estado, p. 248. 
religião e cultura, da qual o demônico é um ponto de referência privilegiado, é particularmente importante para a antropologia xamanística Guarani. Um exemplo é dado pelas ideias do já citado Pierre Clastres. No caso desse filósofo e etnólogo francês, o xamanismo insere-se em sua antropologia política, ou seja, todas as dimensões da vida social indígena (inclusive o religioso) são perpassadas pelas relações políticas de poder enquanto fato social total, no sentido que Marcel Mauss dá ao termo. Assim, a lógica das sociedades ameríndias é a dura luta para a manutenção de uma sociedade do contra-poder, ou seja, contrária à instalação de estruturas sociais que centralizem o poder, o uno (absoluto): essa centralização seria a gênese da formação do Estado. Essa é a tese central de $A$ Sociedade contra o Estado, a ideia de que é preciso estabelecer relações de poder sem instaurar uma instituição a partir de onde unicamente se legitimaria esse mesmo poder.

O poder ameríndio (expresso também nas sociedades Guarani), nesse caso, é não ter poder (poderia ser uma tensão demônica, no plano de sentido?). Os xamãs inscrevem-se nessa lógica: lidam com poderes religiosos, caminham por lugares de poder, mas não podem legitimar suas ações em estruturas religiosas de onde emanaria uma centralidade desse poder. Uma absolutização de formas culturais ou a grave e deletéria diluição da ambiguidade do demônico, em sentido tillichiano. Isso é particularmente difícil, só para ficar nesse exemplo, no contexto das terras indígenas com presença Guarani e Kaiowá no sul de Mato Grosso do Sul (como no já citado município de Dourados), onde as políticas indigenistas são reguladas por órgãos estatais que, várias vezes, legitimam o poder dentro de uma lógica heteróclita às tradições nativas indígenas. Além disso, a experiência religiosa Guarani se vê na fronteira de relações com outras formas de poder religioso (instauradas pela presença de múltiplos missionamentos cristãos) que, utilizando a linguagem de Tillich, chegaram como poderes heterônomos às formas culturais nativas: o risco da distorção demônica, muitas vezes, implicou na destruição demoníaca ao propor/impor-se à experiência religiosa Guarani experiências ditas incondicionais mas que, para eles Guarani, não possuem necessariamente esse sentido. O xamãs tradicionais, hoje, se veem no constante processo de ressignificação de suas intencionalidades e práticas, pois precisam reordenar seu universo de sentido 
(ideias, mentalidades, cultura material) em territorialidades que não contam com formas culturais nativas tão favoráveis a uma expressão mais transparente e positiva de sua substância religiosa nativa, se podemos assim nos exprimir em linguagem miliciana. A crítica necessária de se manter a ambiguidade demônica em contextos sociais que tentam eliminar essas ambiguidades, a preço da perda total das expressões de sentido da vida, é uma perspectiva interessante em torno da relação entre xamanismo e o próprio conceito de demônico.

3. Por fim, voltando à questão da ambiguidade do demônico. De forma mais ampla é possível pensar que ela pode ter uma força epistemológica importante na relação entre etnologia (e as demais ciências do social) e a teologia, tomada por Tillich no sentido da "ciência" das representações do incondicional. Ambas não podem renunciar suas ambiguidades como campo hermenêutico expressivo. A antropologia da religião, no que diz respeito ao estudo do xamanismo Guarani, ainda insiste em certa leitura desse mesmo xamanismo como traço de sobrevivência de certa cultura nativa pretérita explorada e sacrificada por uma lógica de confinamento e desterritorialização das terras tradicionais (chamadas de Tekoha, no Guarani) por parte do Estado Nacional e pela lógica de uma evangelização predatória e demonizadora por parte de missões cristãs (principalmente os missionamentos evangélicos, pentecostais e neopentecostais) ${ }^{19}$. Os chamados pastores indígenas, segundo afirmam Antonio Brand e KatyaVietta, mantêm-se e legitimam-se nesse cenário caótico, mais do que os xamãs, porque conseguem operar ações homológicas típicas desses mesmos xamãs tradicionais (aconselhamento, curas, revelações, dentre outros). Claro que essa análise é importante. O que não se deve é perder de vista a possibilidade da, digamos assim, perspectiva demônica da situação, pois não se trata somente de construções homológicas de sentido. Trata-se, também, de construções e experiências heterológicas, pois tanto os xamãs tradicionais quanto os pastores indígenas tem que lidar, a partir de formas culturais comuns a ambos, com interpretações e ressignificações de sentido não comuns,

19 Essa perspectiva está muito presente nas análises do historiador Antonio Brand a da antropóloga Katya Vietta. Por exemplo, no texto deles intitulado "Missões Evangélicas e Igrejas Neopentecostais entre os Kaiowá e os Guarani em Mato Grosso do Sul”, p. 219-65. 
contraditórias até, construindo e destruindo suas diferentes fronteiras entre religião e cultura em uma experiência religiosa profundamente ambígua. Essa ambiguidade demônica é importante porque expressa, também, a alteridade dos sujeitos e atores sociais envolvidos nas práticas xamânicas, sejam tradicionais, sejam as ressignificações que essas práticas assumem nos cristianismos hoje dentro das aldeias, não reduzindo o xamanismo a um pretenso traço de sobrevivência de uma cultura pura e nativa que ficou para trás.

Ainda constitui-se em um entrave epistemológico para a antropologia a dependência do demônico em relação à ideia da religião enquanto substância da cultura, pois essa afirmação seria, ela mesma, situada culturalmente. Muito embora não faltem análises etnológicas da exaltação da religião como o núcleo duro de resistência das sociedades Guarani, uma substância (não necessariamente no sentido tillichiano) religiosa que permanece após os processos de aculturação sofrida por esses mesmos povos ${ }^{20}$. Se, para Tillich, o demônico flui da própria essência do Sagrado e perpassa as formas culturais de maneira distorcida, não deixa de referenciar a experiência religiosa como experiência de sentido incondicional como fundamento dessas mesmas culturas. Para a antropologia, por sua vez, o demônico é uma categorização essencialmente cultural. Isso não significa que não expresse a experiência religiosa, mas que não coloca essa experiência como fundamento da cultura. Claro que essa questão vai além do tema do xamanismo. Porém, se devemos manter a ambiguidade para ser justo com a noção de demônico, esse conceito não poderia alertar alguns discursos antropológicos que, ao colocar a religião como manifestação da cultura, não criaria o problema de absolutizar essa cultura como fundamento da religião? A antropologia não estaria imune à crítica da fundamentação, pois o próprio pensamento de Tillich não está. Mas aí já não estaríamos mais no tema específico desse texto. Semeamos essas hipóteses e que

20 Como as análises, nos anos 50 e 60, de Egon Schaden sobre o processo de aculturação desses povos. Para esse autor a religião Guarani foi o núcleo de resistência da identidade cultural desses povos ao avanço do discurso e práticas cristãs nas aldeias. Mesmo que tenha sofrido profundas influências cristãs, os indígenas as assimilaram de tal modo a "[...] não obliterar, mas acentuar ao extremo certos valores centrais da própria doutrina primitiva, reinterpretando ensinamentos do Cristianismo segundo o espírito desta" (SCHADEN, 1969, p. 105). 
o texto seja um ponto de partida, um horizonte para vislumbrar novas possibilidades de pesquisa e diálogo.

\section{Considerações finais}

Dentre as várias afirmações importantes que Paul Tillich faz sobre a religião temos a que toda compreensão dos fenômenos traduzidos por esse termo não pode abandonar suas ambiguidades: aí residiria toda a honestidade de análise. Nos termos do próprio teólogo e filósofo: "religião é a mais alta expressão da grandeza e dignidade da vida; (...) Ainda, religião é também a mais radical refutação da grandeza e dignidade da vida; (...) Essas ambiguidades são o assunto central de qualquer compreensão honesta da religião" (TILLICH, 1976, p. 98). E essa ambiguidade reside no entendimento de que a religião, enquanto função auto-transcendente da vida exige ser, paradoxalmente, a resposta as próprias ambiguidades da vida da qual ela faz parte, ainda que a parte radical de sua fundamentação (substância). Transcende as tensões e conflitos oriundos da finitude: “(...) Porém, ao fazê-lo, ela [a religião] cai em tensões mais profundas, conflitos e ambiguidades" 21 .

Ao estudar os discursos e práticas indígenas xamanísticas Guarani temos um lugar hermenêutico importante para compreender as ambiguidades da religião. Não somente para trazer as Ciências da Religião e Teologia para o diálogo com outros saberes, como a antropologia. Embora Tillich tenha, como limite apontado em sua teologia e filosofia da cultura, privilegiado manifestações culturais artísticas oriundas das elites de seu tempo "[...] e menos as nascidas ou reproduzidas em ambientes populares, indício de sua formação burguesa e eurocêntrica e da proximidade ideológica com a Escola de Frankfurt" (CALVANI, 2010, p. 91), é possível perceber que, no que diz respeito ao conceito de demônico, o mesmo carrega um potencial interpretativo para analisar não somente as ditas manifestações populares, mas processos étnicos de grupos sociais historicamente protagonistas da constituição das alteridades brasileiras. Tragicamente violentados nesse protagonismo, os

21 Os dois trechos originais, respectivamente, são: "Religion is the higuest expression of the greatness and dignity of life [...] These ambiguities are the central subject of any honest understanding of religion", e "But, in doing so, it falls into even profounder tensions, conflicts, and ambiguities". 
xamãs Guarani representam processos culturais que emergem no campo religioso brasileiro mostrando que as experiências religiosas refletem e produzem vínculos de distorção como criação e não somente como apanágio de destruição, uma vez que a ambiguidade não é um mero adjetivo, mas a constituição radical da vivência religiosa. Se a noção tillichiana de demônico surge, dentre outros motivos, para mostrar que as hegemonias cristãs no Ocidente, muitas vezes, se sustentaram em uma pretensa e quimérica positividade teológica (discursos e práticas), principalmente no seu simbolismo maior nomeado por "Deus", essa mesma noção pode ser um caminho mediador (não o ponto final) para o encontro com outras tradições religiosas para as quais os desvios, as distorções e as invenções ambíguas são marcas indeléveis de sua possibilidade. Retomando Tillich, estaríamos aqui diante de uma análise mais honesta para com os outros indígenas e para com nós mesmos. $\mathrm{O}$ que, convenhamos, não é pouca coisa.

\section{Referências}

BRAND, Antonio J. O impacto da perda da terra sobre a tradição Kaiowá/ Guarani: Os difíceis caminhos da palavra. Porto Alegre, 1997. Tese (Doutorado em História). Pontifícia Universidade Católica do Rio Grande do Sul, Porto Alegre, 1997.

BRAND, Antonio J. \& VIETTA, Katya. Missões Evangélicas e Igrejas Neopentecostais entre os Kaiowá e os Guarani em Mato Grosso do Sul. In: WRIGHT, Robin M. (org.) Transformando os Deuses. Igrejas evangélicas, pentecostais e neopentecostais entre os povos indígenas no Brasil. Volume II. Campinas: Editora da Unicamp, 2004.

CALVANI, Carlos E. B. Imagens do Diabo na MPB. In: HIGUET, E. e MARASCHIN, J. (eds.). A Forma da Religião. Leituras de Paul Tillich no Brasil. São Bernardo do Campo: UMESP, 2006.

. Teologia da Arte. Espiritualidade, Igreja e Cultura a partir de Paul Tillich. São Paulo: Fonte Editorial\Paulinas, 2010.

CLASTRES, Pierre. A Sociedade contra o Estado. São Paulo: Cosac Naify, 2003.

FAUSTO, Carlos. Inimigos Fiéis. História, guerra e xamanismo na Amazônia. São Paulo: EdUSP, 2001. 
LEWIS, Ioan. Êxtase Religioso. São Paulo: Perspectiva, 1977.

MELIÁ, Bartomeu et.al. Etnografia Guarani del Paraguay contemporáneo. Los Paí-Tavyterã. Vol. XL, n. 1-2. Asunción: Suplemento Antropológico. Centro de Estudios Antropológicos, 1976.

MURA, Fabio. A procura do bom viver: território, tradição de conhecimento e ecologia doméstica entre os Kaiowá. Rio de Janeiro, 2006. Tese (Doutorado em Antropologia Social). Museu Nacional, Universidade Federal do Rio de Janeiro, Rio de Janeiro, 2006.

. A trajetória dos Chiru na construção da tradição de conhecimento Kaiowá. In: Mana, v. 16, n. 1. Universidade Federal do Rio de Janeiro, 2010, p. 123-50.

NIMUENDAJÚ UNKEL, Curt. As Lendas da Criação e Destruição do mundo como fundamentos da Religião dos Apapocúva-Guarani. São Paulo: Hucitec/EdUSP, 1987.

PESSOA, Fernando. Poesias. Seleção de Sueli Cassal. Porto Alegre: L\&PM, 2002.

RICHARD, Jean (org.). La dimension religieuse de la culture, 1919-1926. Paris/Genebra/Québec: Les Éditions du Cerf/Éditions Labor et Fides/Les Presses de L'Université Laval, 1990.

RODRIGUES DA CRUZ, Eduardo. A Dupla Face: Paul Tillich e a ciência moderna. Ambivalência e Salvação. São Paulo: Loyola, 2008.

SCHADEN, Egon. Aculturação Indígena. São Paulo: Pioneira\EdUSP, 1969. E.P.U./EdUSP, 1974.

. Aspectos Fundamentais da Cultura Guarani. 3.ed. São Paulo:

TILLICH, Paul. Filosofía de la Religión. Buenos Aires: Megápolis, 1973.

. Systematic Theology. Volume Three. Life and Spirit, History and the Kingdom of God. Chicago: The University of Chicago Press, 1976.

. Teologia Sistemática. 5.ed. São Leopoldo: Sinodal, 2005.

. On the Boundary. An Autobiographical Sketch. Wipf and Stock Publishers, 2011.

VIVEIROS DE CASTRO, Eduardo B. A Inconstância da Alma Selvagem. São Paulo: Cosac Naify, 2002.

. Metafísicas Canibais. São Paulo: CosacNaify, 2015.

VV.AA. Povos Indígenas no Brasil. 2001\2005. São Paulo: ISA-Instituto Socioambiental, 2006. 